\title{
Special Theme 1: Globalization in the Era of COVID-19
}

\author{
Seungjun Baek ${ }^{1+}$, Seongeun Kim¹, and Tae-hwan Rhee ${ }^{1}$ \\ ${ }^{1}$ Sejong University, Republic of Korea
}

The unforeseen COVID-19 outbreak has brought dramatic changes to how our world operates. Thanks to significant progress in vaccines and treatments, it is reasonable to hope that we can return to normalcy when many aspects of social and economic life can resume without fear of mortality. Still, many economists think that some of the potential structural changes brought by the COVID-19 pandemic will have long-term implications.

For instance, economic integration and globalization may still prevail but their form could start to change. We have observed the impacts of the COVID-19 on globalization. Trade flows plunged during the early stages of the COVID-19 pandemic. The UN Conference on Trade and Investment estimates a 30\%-40\% decline in foreign direct investment inflows in 2020 . The OAG Aviation data showed a $70 \%$ reduction in international air passenger capacity.

There is also a question about the evolution of the ongoing geopolitical tension between the U.S. and China. In addition, while China is expected to remain a crucial hub in global manufacturing, many firms could explore other markets to diversify their production and supply chain, given the concentration risk exposed during the initial phase of the global pandemic.

This pandemic is still ongoing and many datasets have yet to be available to conduct rigorous analysis. However, given the public interest and potential long-term implications in economic integration that the COVID-19 pandemic may bring in the foreseeable future, we have decided to present a COVID-19 special issue. We consider three papers on related topics.

Waldkirch uses survey data collected by the World Bank's Enterprise Survey unit. The goal of this survey is to understand how firms operate in developing countries, especially where no survey or census data were available. He focuses on the effect of the COVID-19 pandemic on firms' involvement in the world economy, for example, exports, and its differential effects on multinational versus domestic firms. Waldkirch finds that the pandemic has a heterogeneous impact across countries and sectors. In particular, firms that rely on exports have suffered a 
greater decline in their revenues than firms that rely on domestic sales. In addition, a more negative effect falls on multinational firms that rely more on global value chains.

Uttama derives policy implications by examining the effect of regional economic integration (the Association of Southeast Asian Nations [ASEAN]) on trade in products that are used to fight against COVID-19. He uses panel data to reveal that the ASEAN regional trade agreement is a stumbling block to the World Trade Organization's multilateral trading system. To overcome this problematic situation, Uttama suggests that 1) the ASEAN should form region-to-region trade agreements with five major trading partners (Australia, China, Japan, South Korea, and New Zealand) in Asia Pacific regions; and 2) free trade agreement between the ASEAN and European Union may be needed.

Kusumahadi collects the stock return data on 15 countries and uses daily observation during this pandemic to study stock return volatility. He shows that the pandemic greatly increased the volatility in the stock markets globally.

We hope that this special issue helps understand the effect of COVID-19 on the economy and stimulates further research on this issue. 